\title{
„UnderstAID - a platform that helps informal caregivers to understand and aid their demented relatives" - assessment of informal caregivers - a pilot study
}

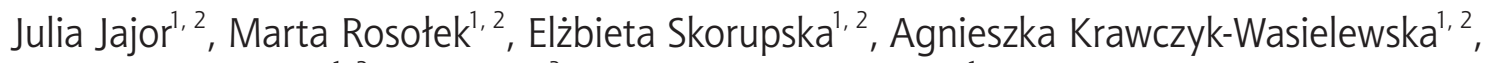 \\ Przemysław Lisiński ${ }^{1,2}$, Ewa Mojs ${ }^{3}$, Włodzimierz Samborski ${ }^{1}$ \\ ${ }^{1}$ Department of Rheumatology and Rehabilitation, Poznan University of Medical Sciences, Poland \\ ${ }^{2}$ Orthopedic and Rehabilitation Hospital, Poznan University of Medical Sciences, Poland \\ ${ }^{3}$ Department of Clinical Psychology, Poznan University of Medical Sciences, Poland
}

\begin{abstract}
Introduction. The number of people with dementia increases. Patients are dependent of informal care provided by their family members, especially spouses, children and friends. As the disease progresses caregiving becomes more complex, stressful and demanding. The needs of informal caregivers are related to the lack of professional support in care, including information about the disease, advise of management of its symptoms and social and financial support. It is therefore important to create an information tool which will assist caregivers in their daily work with people with dementia.

Aim. The aim of the study was the technical evaluation of the information platform for caregivers of patients with dementia.

Material and methods. The study involved 18 caregivers of patients with Alzheimer's disease. The level of GDS scale comprised those between 4 and 7. Platform testing had been carried out from 15 February to 15 March 2015. Evaluation of the platform was made using a technical questionnaire depending on the result of the GDS and the Zarit scale.

Results and conclusions. Platform was rated positively by caregivers (average score 4 out of 5) with the exception of a few areas which received an average rating of 3 . These areas include: usefulness of the guidance provided for the application ( $26 \%$ of respondents assessed it negatively), ease to find the relevant information (25\% negative assessments), application responsiveness (24\% negative assessments) and the quality of the media files (23\% negative assessments). Respondents assessed the platform positively, although some technical issues need improvement.
\end{abstract}

Keywords: dementia, caregivers, software.

\section{Introduction}

Dementia is defined as a set of symptoms caused by a chronic and progressive brain disease. As the disease develops, all life functions are affected and independent functioning in the society is disabled. Those responsible for direct and long-term caretaking are most often informal caregivers, i.e. caregivers not relat- ed in any way to health care [1-3]. Carrying out such duties is associated with intense stress caused by the lack of professional background, emotional attitude towards the demented person or insufficient help by the state or medical institutions [3-5]. This great physical, mental and emotional burden negatively impacts the health of caregivers themselves [6-8]. It may lead to depression, persistent feeling of not being able to 
cope with the existing situation or an impression of life quality decline $[1,9,10]$. Owing to the incidence rate and the difficulties in organising and financing care of demented people, dementia has become one of the top challenges of healthcare system in the 21st century. Even though more than a half (65\%) of dementia patients live in developed countries, the escalation of the above-mentioned problems is directly proportional to an increase in the percentage of the elderly in the global population $[2,11]$. In Poland, almost 92\% of dementia patients stay at their family homes and most often are taken care of by their spouses, who are at similar age and of failing health, at times even disabled. Frequently, caregivers are left on their own, with no professional help or mental support [2, 12]. In Poland, visits of a public health nurse are a form of help for caregivers of demented relatives. However, this kind of help takes the form of everyday nursing care and wound dressing [13]. Only $6 \%$ of Polish dementia caregivers, who participated in studies, described the level of help that the patient receives from the state as satisfactory [12]. To help cope with this status quo, the UnderstAID platform has been created, which was aimed at developing a tool which would support informal caregivers in understanding their demented relatives and in aiding them. The project was awarded in the 5th edition of the Ambient Assisted Living ( $A A L$ ) Joint Programme.

The participants in the programme are: Sekoia Assisted Living ApS; Faculty of Health Science, VIA University College; Danish Alzheimer Association; Skanderborg Municipality; Instituto de Salud Carlos III and The Centre of Supercomputing of Galicia (CESGA); Balidea Consulting and Programming; Provincial Association of Pensioners and Retired People (UDP) from A Coruña, Poznan University of Medical Sciences (PUMS); and Wiktor Dega's Orthopaedic and Rehabilitation Clinical Hospital (ORSK) of Poznan University of Medical Sciences.

\section{Aim}

The study was aimed at the technical assessment of the UnderstAID platform by informal caregivers of persons suffering from dementia.

\section{Material and methods}

18 informal caregivers of individuals with Alzheimer's disease, including 2 men and 16 women aged 34-76 (mean age $57+10.7$ ) participated in the study. To the study, the caregivers who met the following inclusion criteria were qualified:

- informal caregivers, who took care of dementia individuals for more than 16 months,

- informal caregivers were the main non-professional caregivers of the demented individual and did not get paid for caretaking,

- informal caregivers had constant access to computer and the Internet at home,

- patient's dementia was assessed to be 4 or more in the GDS scale.

The exclusion criteria were cognitive impairment, illiteracy and visual or motor dysfunctions.

The study was conducted in accordance with the Declaration of Helsinki and consent of the Bioethical Committee of Poznan University of Medical Sciences dated 8 October 2012 (no. 990/12) was obtained. Before participation, all subjects gave their written consent to participate. The study is part of the Ambient Assisted Living ( $A A L)$ Joint Programme financed by the European Union and dedicated to National Financing Institutions - Agreement no. AAL-2012-5-107.

\section{Method description}

The study was conducted from 15 February to 15 March 2015 at homes of the caregivers on the territory of Poland. All subjects were given 2-month access to the pilot version of the platform. Before the subjects started to use the platform, they filled in the Zarit Caregiver Burden Scale questionnaire. On the scale, 0-20 points indicate no or mild burden that the caregiver experiences as a result of everyday caretaking of a demented relative, $21-40$ points mean mild to moderate burden, whereas above 40 - severe burden.

The subjects were taught how to properly use the UnderstAID platform. They were to download and instal the application by themsleves in order to assess its usability. It was possible to test the platform on a PC, smartphone or tablet. When the testing was over, the subjects evaluated the UnderstAID platform using the author's technical assessment questionnaire (approved by Ambient Assisted Living - AAL). The questionnaire included 11 statements related to technical aspects of the application.

\section{Results}

In the study group, moderate burden in the Zarit scale (20.4 points) was confirmed for $28 \%$ of subjects and severe burden for the remaining part (53.2 points). 
All the subjects with moderate burden (group I) and more than a half of those showing severe burden (group II) confirmed that the buttons were appropriately located in the application (Figure 1).

Answers to question no. 2 of the technical assessment questionnaire gave similar results. The whole of the group I and most of the caregivers from group II agreed that the layout of images in the application was adequate. All the subjects of group I said that the instructions on how to use the application were valuable. In group II, half of the subjects confirmed that the instructions were useful. However, $16 \%$ of the group disagreed on the matter. The caregivers with moderate burden claimed that the application was easy to use. Some of the caregivers (42\%) from the group of severe burden agreed with this statement, whereas

\section{Q1}

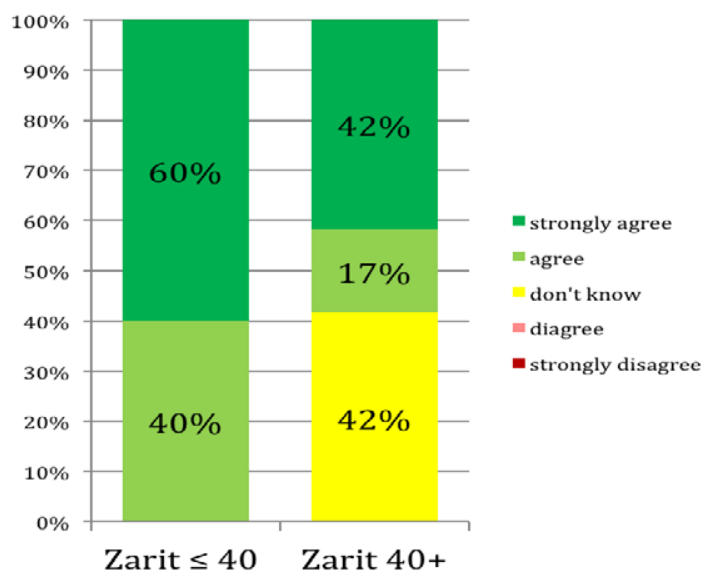

Figure 1. Answers to question no. 1 of the technical assessment questionnaire given by the caregivers depending on the level of burden

Q5

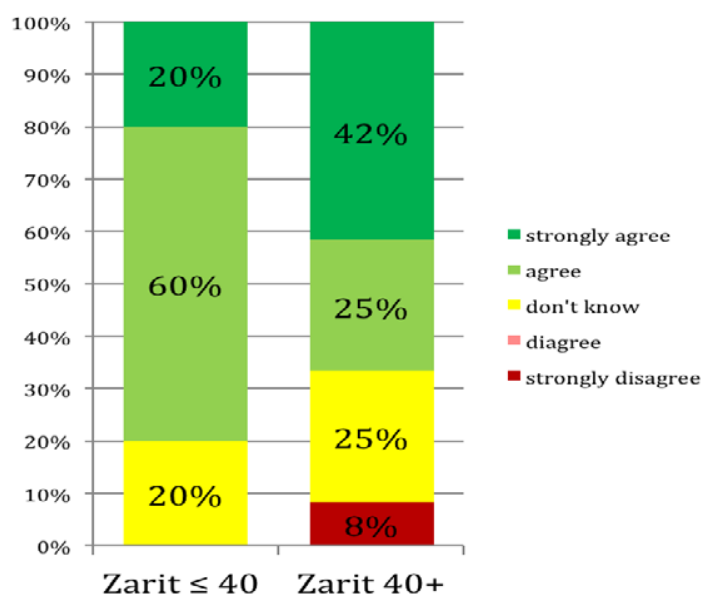

Figure 2. Answers to question no. 5 of the technical assessment questionnaire given by the caregivers depending on the level of burden
$25 \%$ disapproved of it. For the majority of the subjects from both groups, the application was intuitive. On the other hand, $8 \%$ of the subjects from group II were not able to tell how a given action performed in the application would end (Figure 2).

All of the subjects from group I and a big percentage of the subjects from group II confirmed that contrasting colours (text on a given background, colours of illustrations) and the size of the text make the application easy to use. In group II, 16\% of the subjects opposed this statement. For the majority of the subjects from both groups, the way the application could be operated was well adapted to the devices they used. In the group of severe burden, $8 \%$ the of subjects disagreed. The whole of group I and some of the caregivers (41\%) from group II confirmed that they had practically no difficulty finding information they were looking for. In group II, however, some of the subjects (33\%) were not able to find the information they required. Caregivers from group I, unanimously claimed that the quality of multimedia files (videos, images, sound) used in the application was adequate. In group II, only a small number of subjects agreed with this statement. In this group, there were also individuals for whom the quality of the files was insufficient (Figure 3).

The majority of the subjects from group I and some of the subjects from group II said that the application worked fast and without any problems. However, in both groups there were also subjects who disagreed with this statement (Figure 4).

More than a half of the subjects from both groups confirmed that the support option in the application

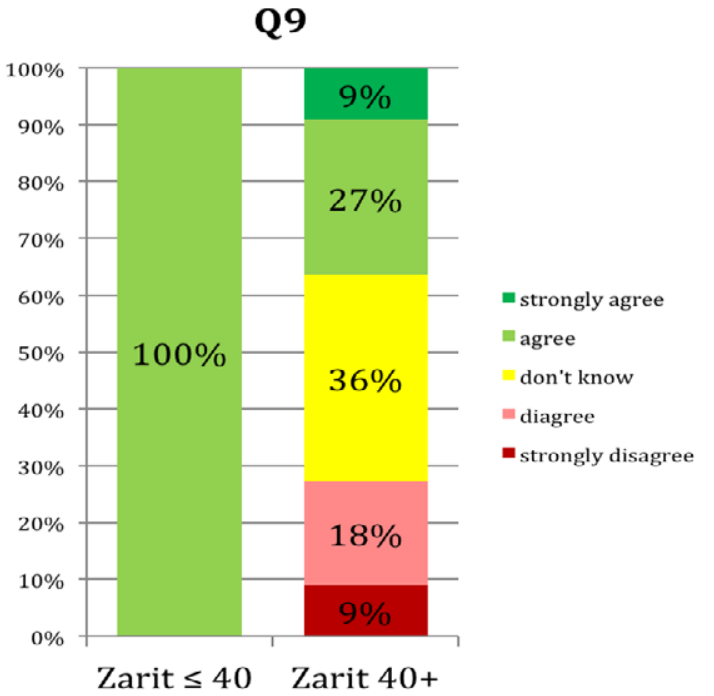

Figure 3. Answers to question no. 9 of the technical assessment questionnaire given by the caregivers depending on the level of burden 


\section{Q10}

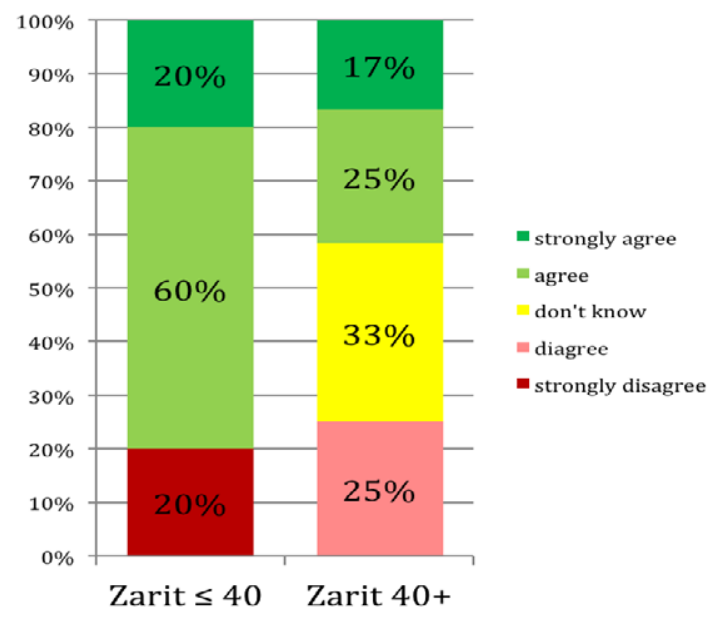

Figure 4. Answers to question no. 10 of the technical assessment questionnaire given by the caregivers depending on the level of burden

\section{Q11}

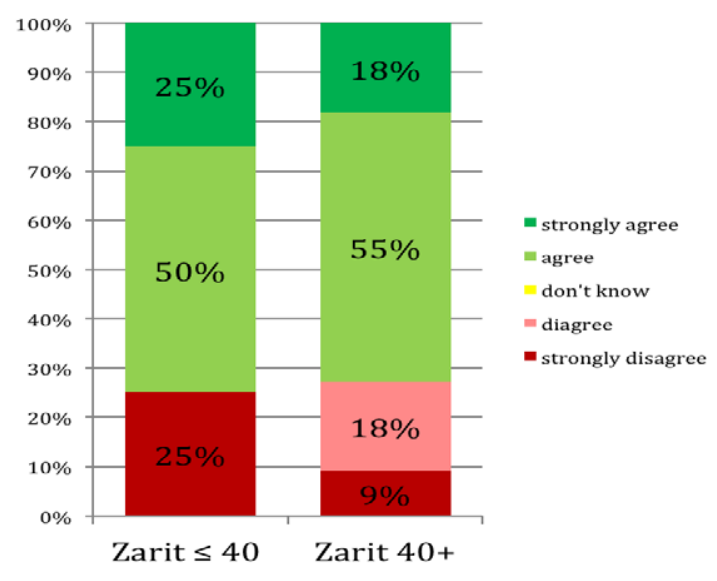

Figure 5. Answers to question no. 11 of the technical assessment questionnaire given by the caregivers depending on the level of burden

was useful. In both groups, however, there were also a few caregivers not satisfied with the "Help" option (Figure 5).

\section{Discussion}

The overall technical assessment of the platform conducted by the informal caregivers is satisfactory. Nevertheless, some technical shortcomings were revealed. Reduced utility of the "Help" function, difficulty in finding specific information, as well as problems with application performance or multimedia files quality were confirmed. A similar e-learning tool proposed by Chambers et al. was assessed much higher [14]. The UnderstAID platform was not evaluated that well owing to some technical aspects, which in the caregivers' opin- ion have not been sufficiently worked up. In the case of UnderstAID, the quality of multimedia files needs to be improved, even though the contrast between colours and font size were evaluated as adequate. Moreover, according to the caregivers the application should be faster and more efficient.

An automated psycho-educational program for caregivers of persons with Alzheimer's disease called Diapason may be another example of such tools. It was assessed to be useful (95\%), comprehesible (100\%) and complex (85\%) but since the study sample was narrow the results cannot be treated as decisive. During the evaluation of the Diapason project, not only quantity but also quality measurements were conducted, which indicated that the approval of the program was little and the expectations of caregivers towards this type of tools were big. These expectations concerned functions such as performance, intuition in using the application or level of personalisation. Caregives do not reject such initiatives and they will be interested in them as soon as such functions are present and their expectations indeed satisfied [15]. The above-mentioned study was another one to indicate that the expectations of potential beneficiaries are high as regards this kind of applications. The results of the pilot study concerning the UnderstAID platform are similar to the results of the two studies just mentioned. Caregivers expect that the platform will be improved as far as the parameters of the application that they were negative about, such as performance and efficiency of the application, are concerned. On the contrary, the majority of the subjects were moderately satisfied with the fact that the application was intuitive for them and all subjects felt that the buttons and images were adequately laid out.

Among the assessed technical aspects of the platform, there were also those on which opinions were divided, namely ease of use of the application or its adaptation to different devices used by caregivers (computers/tablets). A training portal STAR, which is a multilingual e-learning tool and was evaluated by dementia caregivers as very useful and easy to use, can serve as an example to follow [16].

Research done by Vaigankar [17] in a group of informal caregivers of older adults showed that dementia increases the caregiver's burden measured in the Zarit scale to a significant extent. The study on the UnderstAID platform confirmed the same. The majority of subjects experienced severe burden as a result of taking care of a demented person.

The UnderstAID platform obtained a positive opinion from the informal caregivers also because of the 
utility of the platform as an e-learning tool. The caregivers admitted that it is an accessible and a comfortable way of gaining information. Studies by Leslie P. Kernisan et al. confirmed that caregivers of older adults very often treat the Internet as a basic source of information. No age range was given, however, and this is why it cannot be assumed that this conclusion applies also to caregivers advanced in age, who were included in the study group of the UnderstAID project [18]. Similar results were obtained by Hughes et al., which confirms that visiting the websites of Alzheimer Associations significantly enhances knowledge about the disease [19]. The study compares the knowledge of people visiting this kind of websites with the knowledge of those who do not use such sources of information [19]. The most popular keywords looked up by caregivers in the Internet include: "health information", "practical care" and "support". Those who visit the sites usually browse for some general information about caretaking or for more specific issues concerning symptom interpretation, probable disease symptoms or the impact of the disease on the patient's behaviour and the relationship with the diseased person [18]. This kind of information can be found in the UnderstAID platform.

The available literature gives numerous descriptions of initiatives similar to the present study. The EU-financed project STAR, during which an Internet portal aimed at providing online training for dementia caregivers was developed, is a good example [20]. A study by Dillon et al., on the other hand, evaluated 7 websites that gave information about dementia [21]. The study showed [21] that only 3 out of all the tested websites were a source of relatively complex and high-quality information. Therefore, special emphasis should be given to the reliability and scientific relevance of any initiatives aimed at supporting dementia caregivers.

The number of people suffering from dementia is still growing. Together with the progress of Alzheimer's disease or other forms of dementia, institutional care risk is also increasing, which is very often in contrast to patients' desire to stay at their homes [22]. Because of this, it is so crucial to develop a complex online tool through which informal caregivers could gain knowledge about taking care of demented relatives at home. The UnderstAID platform that was tested during the study was proven to provide a great deal of substantive support to the caregivers. However, no studies on alleviating fear or depression in caregivers have been conducted so far. This idea will be taken up, though, in the second phase of the pilot testing.

\section{Conclusions}

The caregivers' assessment of the platform was moderately positive. Data provided by the informal caregivers by means of the technical questionnaire are being currently analysed to be included in a report. The report will form a basis for the modifications to the prototype that is to be tested in the next phase of the pilot testing.

The caregivers expect the UnderstAID platform to be improved with respect to the following technical aspects: the utility of the "Help" option in the application, ease in finding the required information, performance and efficiency of the application, as well as multimedia files quality.

To recapitulate, the platform is most probable to be a useful tool for dementia caregivers but some technical aspects need to be improved.

\section{Acknowledgements}

\section{Conflict of interest statement}

The authors declare that there is no conflict of interest in the authorship or publication of contribution.

\section{Funding sources}

The article written as part of the research grant AAL5/1/2013 and AAL5/2/2013 UnderstAID - a platform that help informal caregivers to understand and aid their demented relatives. Funded by Narodowe Centrum Badań i Rozwoju.

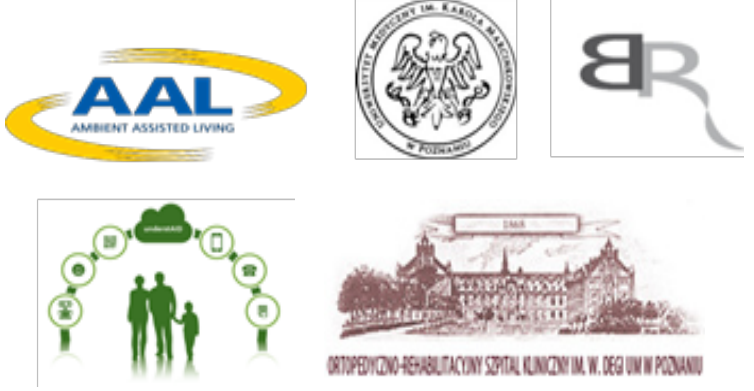

\section{References}

1. Brodaty $H$, Donkin M. Family caregivers of people with dementia. Dialog Clin Neurosc 2009;11(2):217-228.

2. Dang S, Badiye A, Kelkar G. The dementia caregiver a primary care approach. J South Med 2008;101(12): 1246-1251.

3. Commissaris CJ, Jolles J, Verhey FRJr, Kok GJ. Problems of caregiving spouses of patients with dementia. Patient Edu Counsel. 1995;25(2):143-149.

4. Connell CM, Janevic MR, Gallant MP. The costs of caring: impact of dementia on family caregivers. J Geriatr Psych Neur. 2001;14(4):179-187.

5. Kaczmarek M, Durda M, Skrzypczak M, Szwed A. Ocena jakości życia opiekunów osób z chorobą Alzheimera (Eva- 
luation of life quality of people with Alzheimer's disease caregivers). Gerontol Pol. 2010;18(2):86-94.

6. Andren S, Elmstahl S. The relationship between caregiver burden, caregivers' perceived health and their sense of coherence in caring for elders with dementia. J Clin Nurs. 2008;17(6):790-799.

7. Alspaugh ME, Stephens MA, Townsend AL, Zarit SH, Greene R. Longitudinal patterns of risk for depression in dementia caregivers: objective and subjective primary stress as predictors. Psychol Aging 1999;14(1):34-43.

8. Roopalekha J, Latha KS, Bhandary PV Burden and coping in informal caregivers of persons with dementia: a cross sectional study. Online J Health Allied Sci 2010; $9(4): 1-6$.

9. Bruvik FK, Ulstein ID, Ranhoff AH, Engedal K. The quality of life of people with dementia and their family carers. Dement Geriatr Cogn. 2012;34(1):7-14.

10. Etters L, Goodall D, Harrison BE. Caregiver burden among dementia patient caregivers: a review of the literature. J Am Acad Nurse Pract 2008;20(8):423-428.

11. Bosanquet $N$. Socioeconomic impact of Alzheimer's disease. Int J Geriatr Psych. 2001;16(3):249-253.

12. Durda M. Organizacja opieki nad osobami z demencją w Polsce na tle krajów rozwiniętych i rozwijających się. (Organization of care for people with dementia in Poland in the context of developed and developing countries). Gerontol Pol. 2010;18(2):76-85.

13. Krawczyk-Wasielewska A, Malak R, Mojs E, Samborski W, Millan-Calenti JC, Maseda A, Gregersen R, Maibom $K$. Recommendations of the Alzheimer's Disease International concerning the care of patients with dementia and the situation in Poland. Eur Sci J. 2014;Spec. Ed. Vol. 3: 166-169.

14. Chambers M, Connor S. Technology as an aid to coping with caring: a usability evaluation of a telematics intervention. Stud Health Technol Inform. 2001;84(2):11301134.

15. Cristancho-Lacroix V, Wrobel J, Cantegreil-Kallen I, Dub T, Rouquette A, Rigaud AS. A web-based psychoeducational program for informal caregivers of patients with Alzheimer's disease: a pilot randomized controlled trial. J Med Internet Res. 2015 May 12;17(5):117.

16. Hattink $B$, Meiland $F$, van der Roest $H$, Kevern P, Abiuso F, Bengtsson J, Giuliano A, Duca A, Sanders J, Basnett F, Nugent C, Kingston P, Dröes RM. Web-based STAR e-learning course increases empathy and understanding in dementia caregivers: results from a randomized controlled trial in the Netherlands and the United Kingdom. J Med Internet Res. 2015;17(10).

17. Vainkangar JA, Chong SA. Care participation and burden among informal caregivers of older adults with care needs and associations with dementia. Int Psychogeriatr. 2015;19:1-11.

18. Kernisan LP, Sudore RL, Knight SJ. Information-seeking at a caregiving website: a qualitative analysis. J Med Internet Res. 2010;12(3).

19. Hughes ML, Lowe DA, Shine HE, Carpenter BD, Balsis S. Using the Alzheimer's Association web site to improve knowledge of Alzheimer's disease in health care providers. Am J Alzheimers Dis Other Demen. 2015;30(1): 98-100.

20. Boyd K, Nugent C, Donnelly M, Bond R, Sterritt R, Hartin $P$. An investigation into the usability of the STAR training and re-skilling website for carers of persons withdementia. Conf Proc IEEE Eng Med Biol Soc. 2014;4139-42.

21. Dillon WA, Prorok JC, Seitz DP. Content and quality of information provided on canadian dementia websites. Can Geriatr J. 2013;16(1):6-15.

22. Stucki RA, Urwyler $P$, Rampa L, Müri R, Mosimann UP, Nef T. A web-based non-intrusive ambient system to measure and classify activities of daily living. J Med Internet Res. 2014;16(7):175.

Acceptance for editing: 2015-11-10 Acceptance for publication: 2015-12-31 